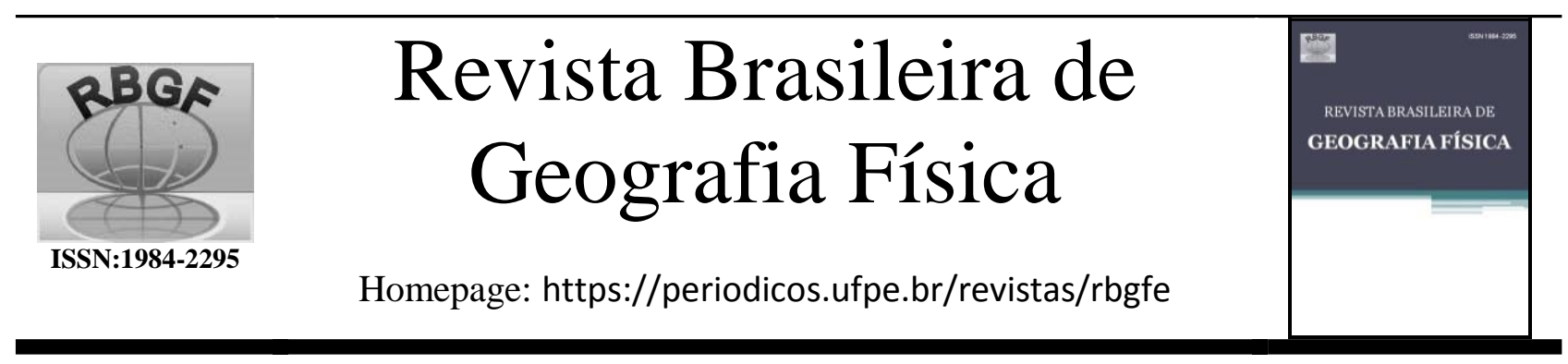

\title{
Identificação das causas climáticas dos eventos extremos e dos impactos dos ENOS Canônico e Modoki nas macrorregiões de Alagoas
}

\begin{abstract}
Djane Fonseca Da Silva ${ }^{1}$, Pedro Fernandes De Souza Neto ${ }^{2}$, Silvania Donato Da Silva ${ }^{3}$; Maria José Da Silva Lima ${ }^{4}$; Iara Bezerra Da Silva Cavalcante ${ }^{4}$; Sherlly Teles De Oliveira ${ }^{4}$, Helen Da Silva Mendonça ${ }^{4}$; Barbara Alves Batista ${ }^{3}$; Lucas Henrique Dos Santos ROCHA ${ }^{3}$; Henrique Ravi Rocha De Carvalho Almeida ${ }^{5}$; Marcos Paulo Santos Pereira ${ }^{6}$, Lincoln Eloi De Araújo 7

${ }^{(1)}$ Universidade Federal de Alagoas. Campus A. C. Simões, CEP 57000-000, Prof $^{a}$ Dr $^{a}$ do Instituto de Ciências Atmosféricas (ICAT - UFAL); Maceió - AL, Brasil. Autor para correspondência; e-mail djane.silva@icat.ufal.br; ${ }^{(2)}$ Aluno de Pós-graduação em Meteorologia - UFCG, Campina Grande (PB) $;{ }^{(3)}$ Alunos do curso de Bacharelado em Meteorologia, Universidade Federal de Alagoas. Campus A. C. Simões, CEP 57000-000, Instituto de Ciências Atmosféricas (ICAT - UFAL); Maceió - AL, Brasil. ${ }^{(4)}$ Alunas de Mestrado em Meteorologia, Universidade Federal de Alagoas. Campus A. C. Simões, CEP 57000-000, Professor Visitante no Instituto de Ciências Atmosféricas (ICAT - UFAL); Maceió - AL; ${ }^{(5)}$ Prof. Dr. do curso de Engenharia de Agrimensura, Universidade Federal de Alagoas. Centro de Ciências Agrárias (CECA - UFAL) CEP 57000-000, Rio Largo - AL, Brasil, e-mail henrique.ravi@ceca.ufal.br; ${ }^{(6)}$ Prof.Dr. Visitante no ICAT/UFAL, e-mail: $\underline{\text { marcospspereira @ hotmail.com; }}{ }^{7}$ Prof. Dr. UFPB, Campus Rio Tinto (PB), e-mail: lincolneloi@yahoo.com.br
\end{abstract}

Artigo recebido em 25/04/2020 e aceito em 17/07/2021

\section{R E S U M O}

Anomalias de temperatura de superfície do mar que ocorrem em algumas regiões do Oceano Pacífico Equatorial estão sendo estudadas por causarem impactos distintos e originarem-se de maneiras diferentes, são os ENOS, Modoki e Canônico. O objetivo desse trabalho é identificar as causa s climáticas dos eventos extremos ocorridos nas macrorregiões de Alagoas, e ao mesmo tempo, compararos efeitos dos ENOS Canônico e Modoki e suas classes sobre as macrorregiões alagoanas. Os dados de precipitação diária de 21 municípios do Estado de Alagoas foram obtidos através da Agência Nacional de Águas com período de 1963 a 2014. EN Modoki e Fracos promoveram aumento de chuvas na região Leste. Já EN Fortes causaram diminuição de precipitação no Sertão. Eventos de LN Canônica ca usaram aumento significativo nas chuvas das três macrorregiões, mas o efeito foi melhor em LN Forte. Durante as fases do Dipólo do Atlântico, a fase negativa gerou SPI positivo em todo estado, e na fase positiva, houve diminuição do SPI na região Leste, e registro de SPI negativo no Sertão e Agreste. As causas climáticas dos eventos extremos foram a junção das escalas semestral, interanual, escala entre 1-2 anos de ENOS, escala de ENOS estendido e escala de 11 anos (Dipólo e Manchas solares) potencializando os totais pluviométricos locais, e para casos de seca, sua ausência. Verificou-se, a tra vés de análises de agrupamentos, semelhança entre os SPIs da La Niña Fraca e La Niña Canônica, e entre o El Niño Canônico está ligado a o El Niño Forte. Já matematica mente, a s categorias de El Niño e La Niña forte e fraca apresentaram melhores correlações com ENOS Modoki e Canônico, sugerindo padrão para Alagoas.

Palavras-chave. Análises de Onda letas; SPI; Análises de Agrupamentos.

\section{Identification of climatic causes of extreme events and impacts of Canonical and Modoki ENSO on Alagoas macroregions.}

\begin{abstract}
A B S T R A C T
Anomalies of sea surface temperature that occur in some regions of the Equatorial Pacific Ocean are being studied beca use their cause different impacts and originate in different ways, are the ENOS, Modoki and Canonical.

The objective of this work is to identify the climatic causes of the extreme events that occurred in the macro-regions of Alagoas, and at the same time, to compare the effects of ENOS Canonical and Modoki and their classes on the macroregions of Alagoas. The daily precipitation data for 21 municipalities in the State of Alagoas were obtained through the National Water Agency from 1963 to 2014. EN Modoki and low promoted an increase in rainfall in the Eastern region. EN Fortes, on the other hand, caused a decrea se in rainfall in the Sertão. CanonicalLNevents caused a significa nt increa se in rainfall in the three macro-regions, but the effect was better in LN Forte. During the phases of the Atlantic Dipole, the negative phase generated positive SPI across the state, and in the positive phase, there was a decrease in SPI in the East, and a negative SPI record in Sertão and Agreste. The climatic causes of the extreme events were the combination of
\end{abstract}


semiannual, interannualscales, scale between 1-2 years of ENOS, scale of ENOS extended and scale of 11 years (Dipole and sunspots), potentiating the local totalrainfall, and for cases of drought, your absence. It was found, through cluster analysis, similarity between the SPIs of La Niña low and La Niña Canonical, and between El Niño Canonical is linked to El Niño Forte. Mathematically, the categories of El Niño and La Niña strong and weak showed better correlations with ENOS Modoki and Canonical, suggesting a pattern for Alagoas.

Keywords. Wavelet analysis; SPI; Cluster a nalysis.

\section{Introdução}

A variabilidade temporal do Oceano Pacífico é composta por duas componentes: uma, relacionada à escalainteranual do ciclode ElNiñoOscilação Sul (ENOS) e a outra, linearmente independente incluindo toda a variabilidade interdecadal, a Oscilação Decadal do Pacífico (ODP) (Polzin e Hastenrath, 2014). Na escala interanual, a variabilidade no Oceano Pacífico é a principal fonte de influência para o clima de algumas regiões devido ocorrência de ENOS.

As ocorrências de episódios de ENOS, classificados em El Niño (EN) e La Niña (LN), são associados ao aquecimento ou resfriamento anômalos do Oceano Pacífico Central e Leste, que alteram o sistema oceano atmosfera do Oceano Pacífico Equatorial Tropical e, consequentemente, mexe significativamente com a circulação atmosférica, a precipitação (Grimm et al., 2000; Grimm, 2003; 2004), os eventos extremos de precipitação (Grimm e Tedeschi, 2009) sobre a América do Sul (AS), entre outros campos atmosféricos.

Entretanto, recentemente, anomalias de temperatura de superfície do mar (TSM) que ocorrem em algumas regiões do Oceano Pacífico Equatorial estão sendo estudadas como outro tipo de ENOS, classificados como Modoki e Canônico.

O EN Modoki é caracterizado por anomalias positivas de TSM no Oceano Pacífico Central (ASHOK et al., 2007), acompanhados por anomalias negativas de TSM no Oceano Pacífico Leste e Oeste. Já o EN Canônico é caracterizado pelo enfraquecimento dos ventos alísios e o aumento da TSM no Oceano Pacífico Equatorial Leste (Oliveira, 2001). Padrão contrário de resfriamento ocorre durante o La Niña.

Como citado em Grimm e Tedeschi (2009), Ashok et al. (2007) e Weng et al. (2007) mostraram que há diferenças nas influências globais de um ENOS Modoki em comparação com o ENOS Canônico. Ao estudar as influências de El Niño Modoki no clima global, Weng et al. (2007) observaram que algumas áreas que sofrem impactos na ocorrência de um ENOS Modoki são diferentes daquelas afetadas durante um El Niño Canônico. Ashok et al. (2007) mencionaram que em algumas regiões da América do Sul os impactos do EN Modoki são opostos aos do EN canônico, durante junho-julho-agosto-setembro.

Através de uma comparação entre ENOS Modoki e Canônico, na intenção de analisar a sua estrutura e evolução, Kao e Yu (2009) encontraram que ENOS Canônico está associado com processos acoplados de oceano-atmosfera, e depende das variações da termoclina para sua geração e para a inversão de fase. Por outro lado, ENOS Modoki tem as variações mais intensas na TSM, no vento em superfície e no oceano subsuperficial no Oceano Pacífico equatorial quando seu desenvolvimento ocorre a partir da superfície e das forçantes da atmosfera local, tais como a oscilação de Madden-Julian e as monções da Ásia e da Austrália.

Bonfim e Da Silva (2019) verificaram para a Bacia hidrográfica Aguapeí-Peixe (SP) que quando relacionadas as classes dos eventos classificados pelo SPI - Standardized Precipitation Index - com os tipos de ENOS, constatou-se que em anos de El Niño Canônico há uma maior possibilidade de ocorrência de chuvas extremas, assim como, em La Niña Canônica, para as secas leves. Conclui-se que a associação entre o SPI e os tipos de ENOS mostrou-se relevante para os estudos de previsões climáticas, podendo auxiliar os diferentes setores e evitando os transtomos causados por extremos de precipitação.

As diferenças verificadas nas anomalias de precipitação em várias partes do globo em decorrência dos diferentes tipos de ENOS, incluindo ENOS Modoki e Canônico, já justifica a necessidade de pesquisar sobre os impactos dos diferentes ENOS.

Durante as variações de TSM do Oceano Pacífico Norte devido eventos de ENOS são notáveis mudanças na circulação atmosférica e na precipitação em escala global que, consequentemente, influenciam significativamente a frequência de eventos extremos de precipitação em várias regiões do Brasil (Grimm e Tedeschi, 2009).

McKee et al. (1993) propuseram o Índice de Precipitação Normalizada para quantificar o 
déficit de precipitação em diversas escalas de tempo, identificando, classificando e dando a intensidade do evento extremo. $O$ interesse na utilização desse índice no monitoramento de secas é relativamente recente no Brasil, tendo como exemplos, Brunini et al. (2001) e Santos e Anjos (2001), que utilizaram o SPI para monitorar secas nos Estados de São Paulo e Pernambuco, respectivamente.

Macedo et al. (2010) aplicaram o SPI para o Estado da Paraíba e detectaram 24 eventos de secas, sendo a região do semiárido paraibano a que apresentou a maior quantidade de secas, possivelmente devidoà ação do fenômeno El Niño.

Santos et al. (2017), utilizando o SPI para a Amazônia Oriental, detectaram que sua região nordeste possui mais eventos secos que chuvosos. Nas demais regiões (central e sul) a situação é inversa, isto é, existem mais eventos de chuva, porém de pouca duração. Adicionalmente, a região sul da Amazônia Oriental apresentou seca mais severa e prolongada. Os autores associaram os eventos citados à variabilidade climática que ocorre nos Oceanos Atlântico (Dipólo do Atlântico) e Pacífico (ENOS).

O objetivo desse trabalho é identificar as causas climáticas dos eventos ex tremos ocorridos nas macrorregiões de Alagoas, e ao mesmo tempo, comparar os efeitos dos ENOS Canônico e Modoki e suas classes sobre as macrorregiões alagoanas.

\section{Materiais e métodos}

Área de Estudo e Dados

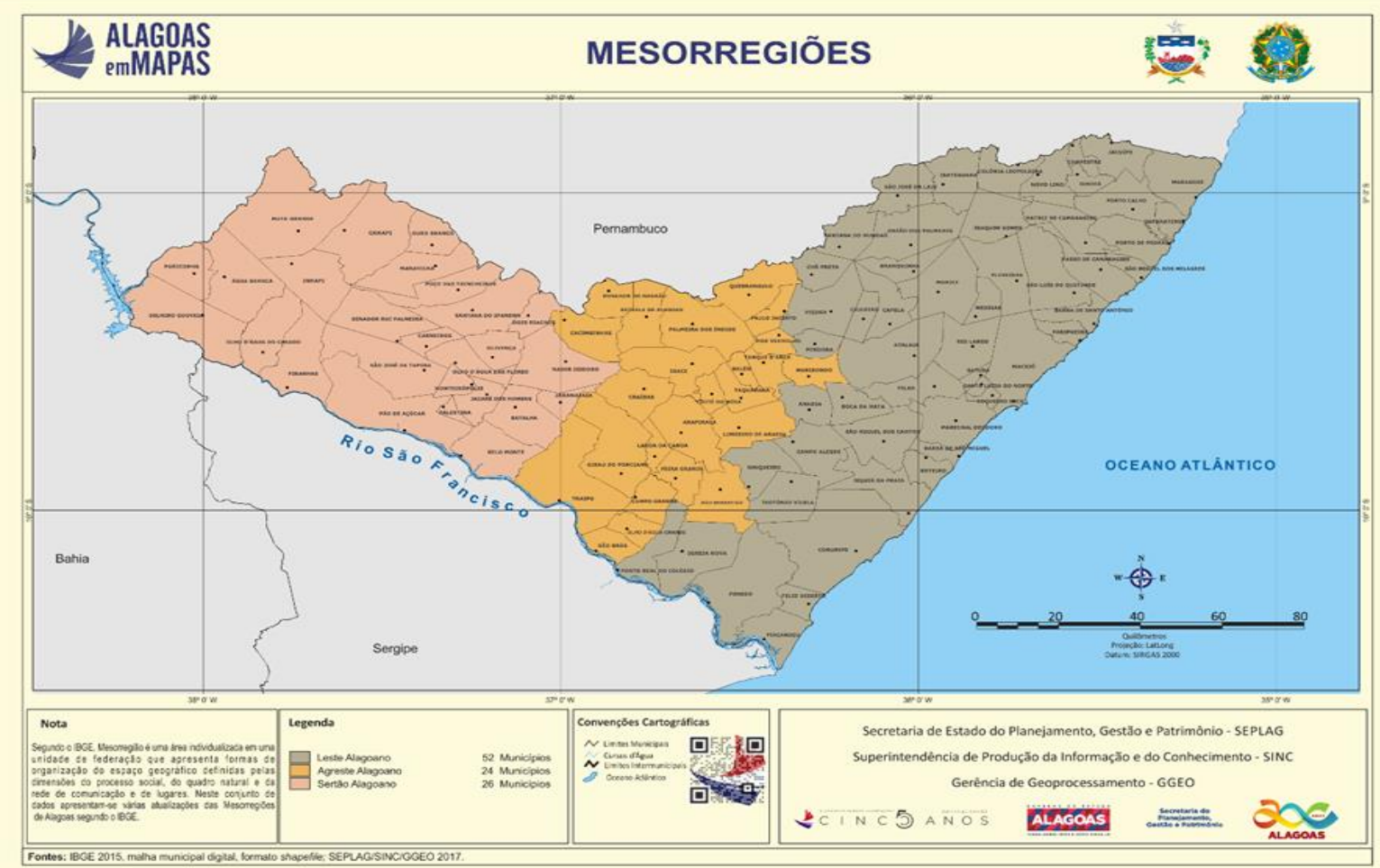

Figura 1. Mapa do Estado de Alagoas e suas mesorregiões. Fonte: SEPLAG (2017).

Neste estudo foi analisado o SPI de eventos de ENOS para vinte e um (21) municípios do Estado de Alagoas (Figura 1), o qual é dividido em três (3) macroregiões: Leste alagoano, Agreste alagoano e Sertão alagoano.
Os dados de precipitação diária de 21 municípios do Estado de Alagoas (Tabela 1) foram obtidos através da Agência Nacional de Águas (ANA) e não apresentaram dados faltosos. Esses dados foram tratados para o cálculo do SPI e o período dos mesmos é de 1963 a 2014. 
Tabela 1. Lista dos municípios que compõem a pesquisa.

\begin{tabular}{lrr}
\hline Municípios & Longitude $\left(^{\circ}\right)$ & Latitude $\left({ }^{\circ}\right)$ \\
\hline Maceió & $-35,7353$ & $-9,6658$ \\
\hline Arapiraca & $-36,6611$ & $-9,7525$ \\
\hline Atalaia & $-36,0227$ & $-9,5019$ \\
\hline Murici & $-35,94$ & $-9,3$ \\
\hline Maragogi & $-35,2225$ & $-9,0122$ \\
\hline Delmiro Gouveia & $-37,93$ & $-9,7$ \\
\hline Palmeira dos índios & $-36,6275$ & $-9,40722$ \\
\hline Igreja Nova & $-37,95$ & $-9,06$ \\
\hline Batalha & $-37,6$ & $-9,33$ \\
\hline Pão de Açúcar & $-37,63$ & $-9,33$ \\
\hline Piaçabuçu & $-36,5$ & $-10,73$ \\
\hline Piranhas & $-37,15$ & $-9,03$ \\
\hline Traipu & $-37,15$ & $-9,2$ \\
\hline Flexeiras & $-35,7808$ & $-9,1975$ \\
\hline Santana do Ipanema & $-37,2452$ & $-9,3783$ \\
\hline Penedo & $-36,5863$ & $-10,2903$ \\
\hline Porto calvo & $-35,3983$ & $-9,045$ \\
\hline São Miguel dos Campos & $-36,0936$ & $-9,7811$ \\
\hline São Luís do Quitunde & $-35,5611$ & $-9,31833$ \\
\hline Santana do Mundaú & $-36,2222$ & $-9,16805$ \\
\hline Matriz do Camaragibe & $-35,5333$ & $-9,15166$ \\
\hline
\end{tabular}

Métodos:

Índice de Precipitação Normalizada (SPI)

Criado por McKee et al. (1993) o cálculo do SPI se inicia determinando uma função de densidade de probabilidade (f.d.p.) que descreve as séries temporais. A distribuição gama possui bom ajuste para variáveis contínuas que tenham limite inferior ou igual a zero e não possuem limite superior, por isso, é largamente utilizada para o estudo de séries históricas de precipitação (WILKS, 2006 Apud SANTOS et al, 2017).

A função gama é dada por:

$$
g(x)=\frac{X^{\alpha-1} * e^{\frac{-x}{\bar{\beta}}}}{\beta^{\alpha} \Gamma(\alpha)} \operatorname{para} X>0
$$

Sendo: $\alpha>0$ parâmetro de forma; $\beta>0$ parâmetro de escala; $x>0$, a quantidade de precipitação $(\mathrm{mm})$ e $\Gamma(\alpha)$ função gama completa. Para estimativa dos parâmetros $\alpha$ e $\beta$ da distribuição gama utilizou-se o método:

$$
\alpha=\frac{1}{4 A}\left(1+\sqrt{1+\frac{4 A}{3}}\right) \mathrm{e} \hat{\beta}=\frac{\bar{x}}{\alpha},
$$

Em que: $\bar{x}$ a precipitação média e,

$$
A=\ln (\bar{x})-\frac{\Sigma \ln (x)}{n} \text {, }
$$

Sendo n o número de observações.

Deste modo, a distribuição acumulativa é então transformada em distribuição probabilidade 
normal com média igual a zero e desvio padrão igual a um. Em seguida, a probabilidade acumulada de ocorrência de cada valor mensal é estimada. Aplica-se a essa probabilidade a função normal inversa para encontrar o valor do SPI.

De acordo com Santos et al (2017) o SPI nada mais é que, a diferença da precipitação observada em relação à média do intervalo de tempo específico 4:

$\mathrm{SPI}=\mathrm{Z}_{\mathrm{i}}=\frac{(\mathrm{Pi}-\overline{\mathrm{Pl}})}{\sigma \mathrm{i}}$

Em que: Pi - Precipitação observada no período, $\overline{\mathrm{P}} \mathrm{i}$ - Precipitação média do período em questão e $\sigma i$ - Desvio padrão da precipitação.

Após o cálculo do SPI, a precipitação total para um período de tempo específico recebe um valor adimensional correspondente a uma classe (Tabela 02). Nesta Tabela são ilustradas as categorias de SPI, baseadas nas descritas por McKee et al. (1993). Foram gerados os valores de SPI para as situações: ENOS (EN e LN) Forte/Moderado/Fraco, ENOS Canônico e Modoki, Dipólo Positivo e Negativo. O SPI foi gerado para as 3 macroregiões de Alagoas: Leste alagoano, Agreste e Sertão alagoano. Os anos desses eventos, escolhidos para análise estão nas Tabelas 3 a a 4 :

Tabela 2. Classificação dos períodos secos e chuvosos de acordo com valores de SPI.

\begin{tabular}{ll}
\hline Valores de SPI & Classes \\
\hline$<-2,00$ & Seca Extrema \\
\hline$-1,99$ a $-1,50$ & Seca Severa \\
\hline$-1,49$ a $-1,00$ & Seca Moderada \\
\hline$-0,99$ a $-0,49$ & Seca Leve \\
\hline$-0,48$ a 0,49 & Quase normal \\
\hline 0,50 a 0,99 & Chuva Leve \\
\hline 1,00 a 1,49 & Chuva moderada \\
\hline 1,50 a 1,99 & Chuva Severa \\
\hline$>2,00$ & Chuva Extrema \\
\hline
\end{tabular}

Fonte: Autor (2019); Modifica do de McKee et al. (1993).

Os valores de SPI (Tabela 2) positivos significam superioridade à média de precipitação, enquanto valores negativos significam precipitação menor que a média. $\mathrm{O}$ valor zero corresponde à precipitação média.

Software Surfer e anos de eventos extremos de ENOS

Utilizou-se o software surfer (com licença pessoal/particular) para gerar mapas de distribuição espacial dos valores de SPI durante eventos extremos em Alagoas, apontando áreas críticas, secas e chuvosas, impactadas pelos fenômenos de ENOS nas categorias Forte, Moderado e Fraco (Tabela 3a e 3b), ENOS Modoki e Canônico (Tabela4) e DipóloPositivoe Negativo (Tabela 5).

Os dados que geraram as composições de mapas têm como período:

Tabela 3a. Anos de El Niño utilizados no estudo. Fonte: CPTEC (2017).

\begin{tabular}{lll}
\hline Forte & Moderado & Fraco \\
\hline $\mathbf{1 9 7 2 - 1 9 7 3}$ & $1965-1966$ & 1963 \\
\hline $\mathbf{1 9 8 2 - 1 9 8 3}$ & $1968-1970$ & $1976-1977$ \\
\hline $\mathbf{1 9 9 1 - 1 9 9 3}$ & $1986-1988$ & $1977-1978$ \\
\hline $\mathbf{1 9 9 7 - 1 9 9 8}$ & $1994-1995$ & $1979-1980$ \\
\hline
\end{tabular}




\begin{tabular}{lll}
\hline- & $2002-2003$ & $2004-2005$ \\
\hline- & - & $2006-2007$ \\
\hline- & - & $2009-2007$ \\
\hline
\end{tabular}

Tabela 3b. Anos de La Niña utilizados no estudo. Fonte: CPTEC (2017).

\begin{tabular}{lll}
\hline Forte & Moderado & Fraco \\
\hline $\mathbf{1 9 7 3 - 1 9 7 6}$ & $1964-1965$ & $1983-1984$ \\
\hline $\mathbf{1 9 8 8 - 1 9 8 9}$ & $1970-1971$ & $1984-1985$ \\
\hline $\mathbf{2 0 0 6 - 2 0 0 7}$ & $1998-2001$ & $1995-1996$ \\
\hline $\mathbf{2 0 0 7 - 2 0 0 8}$ & - & -
\end{tabular}

Tabela 4. Anos de ENOS Canônico e Modoki utilizados. Fonte: Grimm e Tedeschi (2009).

\begin{tabular}{lllll}
\hline & DJF & MAM & JJA & SON \\
\hline El Niño & $1982,1986,1991$, & $1983,1987,1992$, & $1982,1983,1987$, & $1982,1987,1997$, \\
Canônico (ENC) & $1997,2002,2006$. & $1993,1998$. & $1991,1997,2009$. & $2002,2006,2009$. \\
\hline El Niño Modoki & $1990,1991,1994$, & $1991,1994,1995$, & $1991,1992,1994$, & $1986,1991,1994$, \\
(ENM) & $2002,2004$. & $2003,2005$. & $2002,2004$. & $2004,2009$. \\
\hline La Niña & $1984,1988,1996$, & $1985,1988,1989$, & $1981,1984,1985$, & $1984,1985,1988$, \\
Canônica (LNC) & $1998,1999,2005$, & $1996,1999,2007$. & $1988,1999,2007$. & $1995,1998,1999$, \\
& 2007. & & & 2007. \\
\hline La Niña Modoki & $1988,1998,1999$, & $1989,1999,2000$, & $1998,1999,2008$. & $1983,1984,1988$, \\
(LNM) & $2000,2007,2008$. & $2001,2008$. & & $1998,1999,2000$, \\
& & & & 2008. \\
\hline
\end{tabular}

Conforme metodologia de Grimm e Tedeschi (2009) valores em vermelho da Tabela 4 são coincidentes nas duas categorias de anos. Os anos que se enquadram nas duas categorias foram retirados do cálculo dos compostos para evitar a contaminação de um tipo de ENOS no outro.

Tabela 5. Anos de ocorrência do Dipolo do Atlântico. Fonte: Andreoli e Kayano (2007).

\begin{tabular}{cc}
\hline Fase Positiva & Fase Negativa \\
\hline $1951,1953,1954,1956,1958,1966,1969,1970$, & $1949,1964,1965,1971,1972,1973,1974,1977$, \\
$1978,1979,1980,1981,1983,1992,1997$ & $1984,1985,1986,1989$ \\
\hline
\end{tabular}

Análises de Ondeletas

Após o cálculo do SPI, os mesmos foram submetidos à análise de ondeletas através do software Matlab. A aplicabilidade das análises de ondeletas se dá principalmente porque permite decompor uma série temporal em diferentes níveis de resoluçãotempo-frequência e, então determinar, as componentes da variabilidade dominante
(Torrence e Compo, 1998). A ondaleta de Morlet é uma exponencial complexa modulada por uma Gaussiana (Andreoli et al., 2004) e é dada pela seguinte expressão:

$\psi(\mathrm{t})=e^{i \omega n} e^{-\eta^{\mathrm{x}} / 2}$ 
Em que: $\eta=t / s$, onde té o tempo, s é a escala da ondaleta em função do tempo $(=2 / \mathrm{dt}) \mathrm{e}$ $\omega_{0}$ é uma frequência não-dimensional, escolhidos conforme Andreoli et al. (2004); Todos introduzidos no "script" de programação do Software Matlab®.

O período de anos dos ciclos e a escala temporal dominante foram obtidos por programação no Software Matlab® com comandos específicos.

Cluster Analysis ou Análise de agrupamentos

Os métodos de agrupamentos têm pôr finalidade agrupar indivíduos em classes, de forma que os indivíduos pertencentes a essas classes mantenham características semelhantes em algum aspecto (Guimarães et al., 2013).

Assim, nesta etapa foram submetidos à análise de agrupamentos, os dados de SPI dos eventos extremos, de todas as 5 categorias de ENOS, tanto para El Niño, quanto para La Niña, através do software SPSS versão 20, com licença temporária gratuita.

Essa estatística de análise multivariada tem como objetivo principal classificar os indivíduos de uma população que são conhecidos por suas características, ou seja, mostrar indivíduos semelhantes (Unal et al, 2003; Farias et al, 2005). Foi também aplicado o dendograma, que tem como objetivo, unificar indivíduos em classes ou grupos sucessivamente maiores através da utilização de alguma medida de similaridade ou de distância (Guedes et al, 2010; 2012).

Por fim, segundo Macedo et al. (2010), análise de agrupamentos é utilizada em processos de classific ação e consisteem determinar o nível de similaridade ou dissimilaridade entre indivíduos, aplicando uma função de agrupamento a uma determinada variável (Lima et al, 2010). Para validar/reforçar os resultados da análise de agrupamentos, foram realizadas correlações simples (entre as classes/tipos de El Niño e de La Niña, comprovando matematicamente as semelhanças entre as séries.

Correlação "é uma medida de associação bivariada (força) do grau de relacionamento entre duas variáveis". Para Moore (2007) “A correlação mensura a direção e o grau da elação linear entre duas variáveis quantitativas". O coeficiente de correlação de Pearson (r) é uma medida de associação linear entre variáveis. Sua fórmula é:

$$
r_{X, y}=\frac{\Sigma(X+Y)-\frac{(\Sigma X) x\left(\sum Y\right)}{n}}{\sqrt{\left[\sum X^{2}-\frac{(\Sigma)^{2}}{n}\right] x}\left[\sum Y^{2}-\frac{(\Sigma Y)^{2}}{n}\right]}
$$

Após encontrar os valores dos coeficientes de correlação (r), esses valores passaram pelo teste de significância T-Student para verificar se as correlações tem ou não significância estatística para o tamanho da amostra. $\mathrm{n}=$ número de variáveis observadas

$\sum(\mathrm{Y} . \mathrm{X})=$ somatória dos resultados das multiplicações dos valores da variável $\mathrm{X}$ pela respectiva $Y$.

$\sum \mathrm{X} . \sum \mathrm{Y}=$ soma dos valores da variável $\mathrm{X}$ multiplicado pela soma dos valores da variável Y. $\sum \mathrm{X}^{2}=$ somatória dos quadrados dos valores de cada variável $X$.

$\left(\sum X\right)^{2}=$ quadrado da somatória dos valores da variável $X$.

$\sum \mathrm{Y}^{2}=$ somatória dos quadrados dos valores de cada variável $Y$.

$\left(\sum \mathrm{Y}\right)^{2}=$ quadrado da somatória dos valores da variável Y.

Tal teste foi usado nesse trabalho para considerar significativas ou não, as correlações encontradas.

Para amostras de tamanho $\mathrm{N}>30$, denominadas grandes amostras, as distribuições amostrais de várias estatísticas são aproximadamente normais e melhores como o crescimento de N. Para amostras de tamanho $\mathrm{N}<$ 30, denominadas pequenas amostras, essa aproximação não é boa e torna-se pior com o decréscimo de $\mathrm{N}$, de modo que devem ser introduzidas as modificações convenientes.

Um dos testes de significância mais utilizados é o "T-Student", o qual é bastante utilizado (Kousky e Kayano, 1994; Kayano e Kousky, 1996; Figueroa, 1997; Castro, 2002), e pode ser calculado da seguinte forma:

$\mathrm{tc}=\mathrm{t} / \sqrt{(\mathrm{n}-2)+\mathrm{t}^{2}}$

Sendo: $\mathrm{t}_{\mathrm{c}}=$ valor do percentil e c é o grau de liberdade. Foi usado $\mathrm{p}=0,95$ ou $95 \% ; \mathrm{t}=$ valor do percentil tabelado de acordo com $\cup$ (n-1); n é o número de dados.

\section{Resultados}


Na média dos eventos de EN forte (Figura 2) os menores valores de SPI (negativos) ocorreram no extremo leste alagoano, região também conhecida como Zona da Mata ou Litoral, principalmente no sudeste e nordeste do litoral. O mesmo ocorreu também no Norte do Sertão alagoano. Foram registrados maiores valores de SPI positivos, mesmo sendo EN forte, no norte/nordeste do Estado, já na divisa com Pernambuco, abrangendo áreas de Santana do Mundaú, São José da Lage e Ibateguara; municípios esses bem vegetados e com altitudes mais altas. Com exceção dessa área (em azul) grande parte do Estado, quando ocorreu EN Forte, sofreu com secas. Os valores de SPI variaram de 0,5 (seca leve) a 0,8 (chuva leve).

Quando ocorreram EN moderados em Alagoas (Figura 3) os valores de SPI modif icaram em comparação com EN Forte. O SPI variou de 0,2 (quase normal) a 1,2 (chuva moderada); ou seja, nesse tipo de ENOS o Estado sofre menos com secas e as chuvas ganharam intensidade. Os menores valores de SPI foram registrados no Sertão alagoano e em um núcleo do Litoral Norte, em áreas de Barra de Santo Antônio e São Luís do Quitunde, que durante EN forte (Figura 2) apresentaram SPI positivo. Já durante EN Fraco (Figura 4) os valores de SPI foram próximos aos valores para EN Moderado (Figura 3) mas com intensificação das chuvas no norte/nordeste do Estado, já na divisa com Pernambuco (em azul). Áreas do Agreste e Sertão alagoanos passam a ter SPI com valores positivos, mesmo sendo baixos, passando a condição de Quase normal (SPI entre $0,48$ a 0,49$)$. Menores valores de SPI ocorreram no oeste e norte do Sertão Alagoano, áreas dos municípios de Mata Grande, Canapi, Ouro Branco, Inhapi, Água Branca, Delmiro Gouveia etc., os quais se repetem também durante EN moderado. Desse modo, as chuvas são melhores distribuídas espacialmente durante EN Fraco (Figura 4).

Os valores e a distribuição espacial do SPI em EN Canônico (Figura 5) foram próximas às observadas para EN Forte, no entanto, SPI oscilaram de $-0,5$ (seca leve) a 1,0 (chuva moderada). Vê-se que para EN Canônico, áreas do Litoral e Agreste alagoanos são mais sensíveis e o Sertão alagoano chega a apresentar a categoria quase normal, como também observado na Figura 2 para El Niño forte. Já a configuração de EN Modoki (Figura 6) se assemelha com as de EN Moderadoe EN Fraco (Figura 4). Os valores de SPI variam de $-0,2$ (quase normal) a 1,2 (chuva moderada), não tendo ocorrência de secas leves como em EN Canônico e sendo mais sensíveis aos efeitos do EN Modoki, parte do Agreste e maioria do Sertão alagoano.

Em anos de EN Modoki o Leste alagoano apresenta-se mais seco que o Sertão e Agreste, respectivamente. O mesmo ocorre em eventos de EN Canônico. Já para eventos de EN Forte, o Sertão alagoano apresentou menores SPI $(\sim 0,15)$, e ainda assim, caracterizado como quase normal (MCKEEet al., 1993). Quando ocorremeventos de EN Moderado e Fraco, o Leste alagoano ainda apresenta SPI positivo de até 0,25 , também na categoria normal. Valores menores que este são verificados para o Agreste e Sertão.

Em anos de La Niña Forte (Figura 7) os menores valores de SPI (negativos) ocorreram no extremo Leste alagoano (Zona da Mata ou Litoral e Agreste alagoano. Já o Sertão alagoano ficou com SPI com classificação quase normal. As Áreas do norte/nordeste do Estado, já na divisa com Pernambuco, abrangendo áreas de Santana do Mundaú, São José da Lage e Ibateguara, que apresentaram SPI durante El Niños, repetiram SPI positivos, no entanto, agora com maior valor de 1,4 , ainda na categoria chuva moderada. Para categoria de La Niña Forte não houveram secas no Estado.

$\mathrm{Na}$ ocorrência de LN moderadas em Alagoas (Figura 8) os valores de SPI diminuíram em comparação com LN Forte. O SPI variou de 0,5 (seca leve) a 0,9 (chuva leve). Os menores valores de SPI foram registrados no Agreste alagoano, mas de um modo em geral, o Estado sofre negativamente em eventos de La Niña moderada, visto ter diminuição das chuvas.

Em evento de LN Fraca (Figura 9) os valores de SPI foram próximosaos valores para LN Moderado (Figura 8) mas com intensificação das chuvas no litoral e Agreste alagoano, visto o SPI ter aumentado de $-0,5$ para $-0,4$, passando para categoria quase normal. Na região norte/nordeste do Estado, já na divisa com Pernambuco (em azul) as chuvas também aumentam em relação ao evento moderado, passando de 0,9 para 1,0 , chegando à categoria chuva moderada. Áreas do Sertão alagoano (Mata Grande, Canapi, Ouro Branco, Inhapi, Água Branca, Delmiro Gouveia etc.) sofrem mais com ocorrência de LN Fraca. A distribuição espacial do SPI em LN Canônico (Figura 10) foram próximas às observadas para $\mathrm{LN}$ Forte, no entanto, com SPI oscilando de - 0,3 (quase normal) a 1,2 (chuva moderada), não tendo também áreas com secas no Estado, do mesmo modo que durante LN Forte. Vê-se que também para LN Canônico algumas áreas do Litoral e Agreste alagoanos são mais sensíveis e o Sertão 
alagoano chega a apresentar a categoria quase normal.

A composição de LN Modoki (Figura 11) tende a configurar-se como as de LN Moderada e Fraca. Os valores de SPI variam de $-1,2$ (seca moderada) a 1,4 (chuva moderada), tendo ocorrência de secas leves e moderadas como em LN Moderada. Parte do Sertão alagoano e nordeste do Litoral são mais afetadas durante La Niña Modoki, assim como em La Niñas Moderada a Fraca, enquanto região central do Agreste em

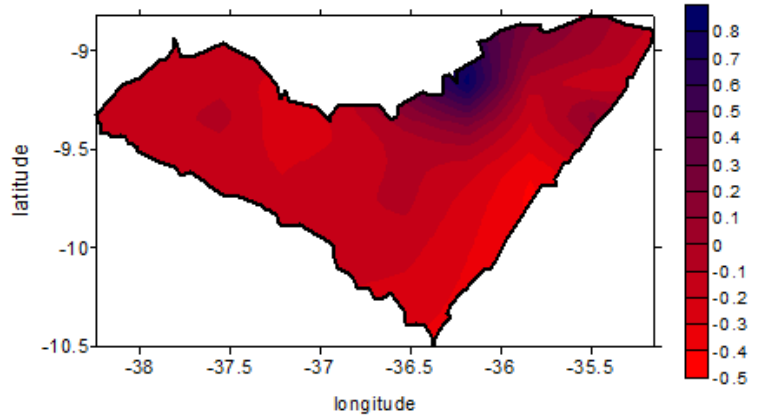

Figura 2. Distribuição espacial do SPI durante El Niño Forte

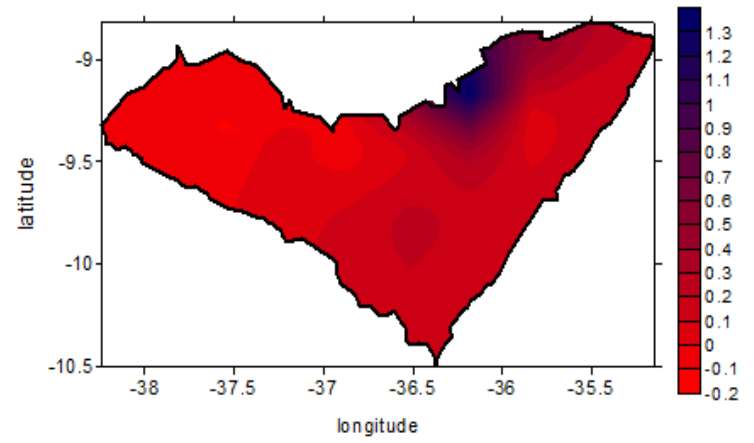

Figura 4. Distribuição espacial do SPI durante El Niño Fraco

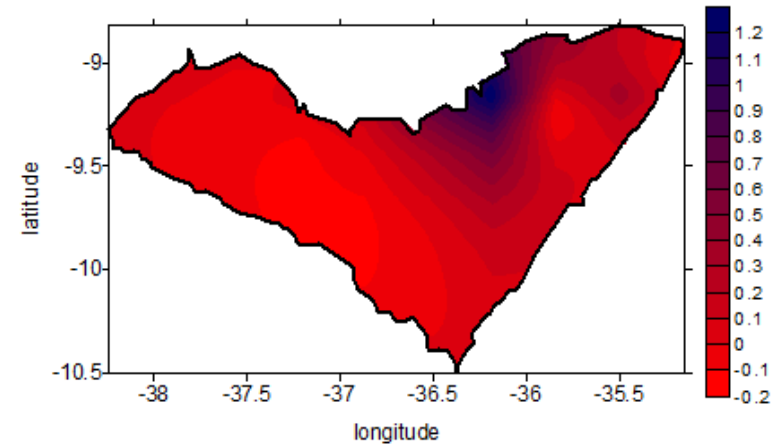

Figura 6. Distribuição espacial do SPI durante El Niño Modoki direção ao norte do Estado, são favorecidas pela ocorrência de La Niña Modoki.

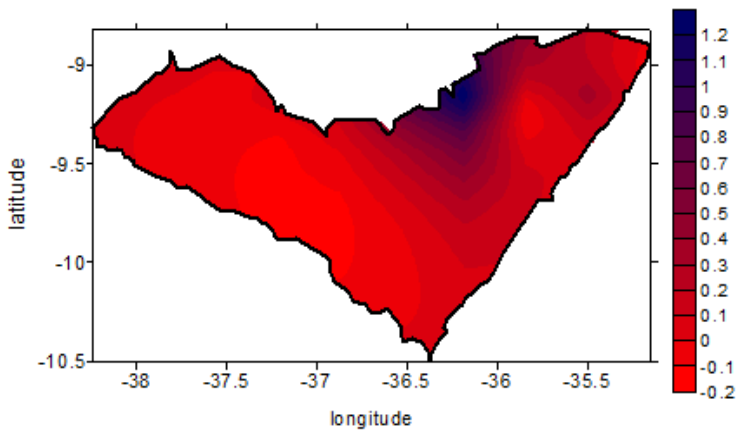

Figura 3. Distribuição espacial do SPI durante El Niño Moderado

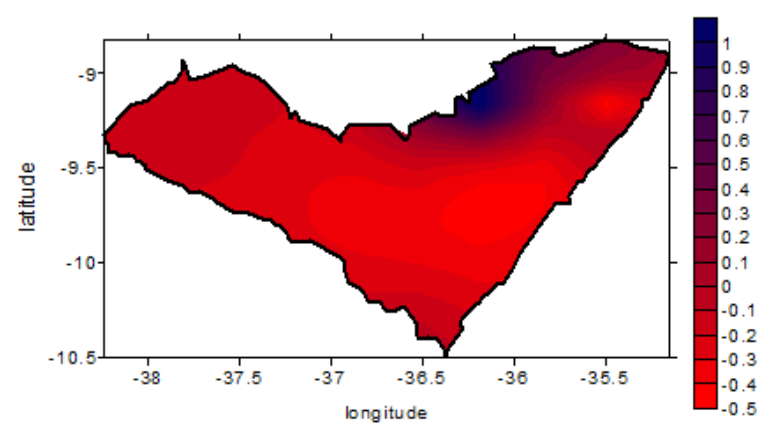

Figura 5. Distribuição espacial do SPI durante El Niño Canônico

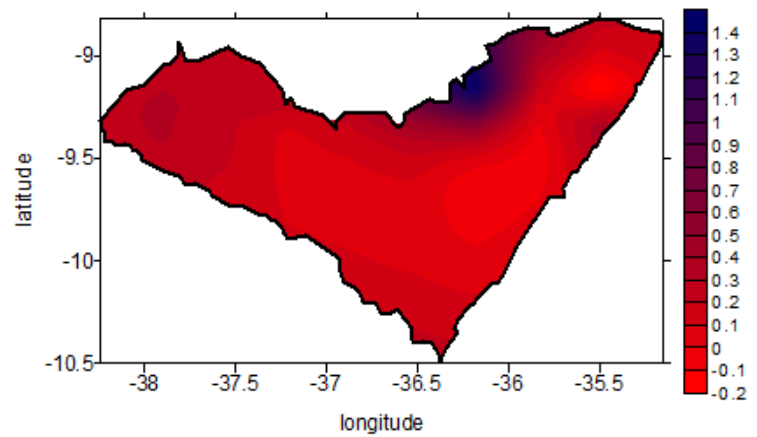

Figura 7. Distribuição espacial do SPI durante La Niña Forte 


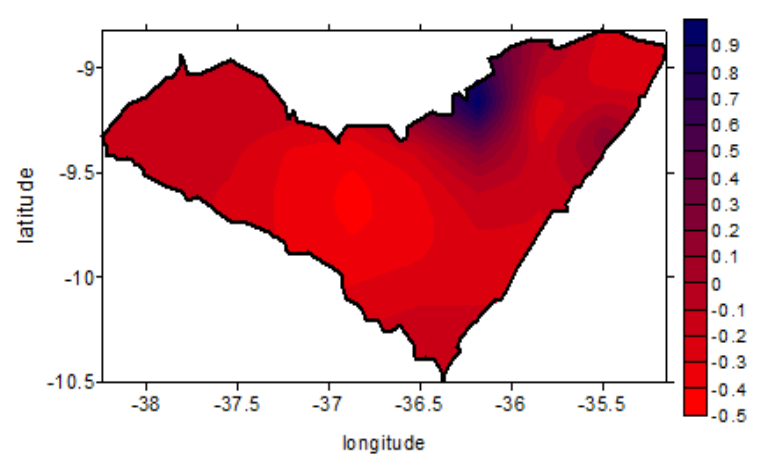

Figura 8. Distribuição espacial do SPI durante La Niña Moderada

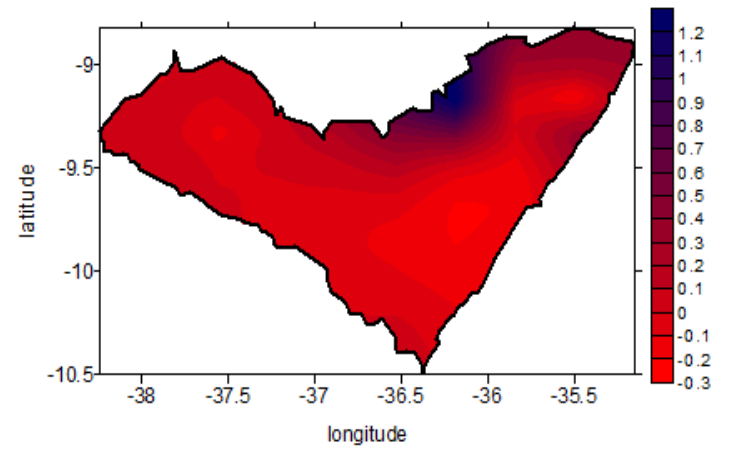

Figura 10. Distribuição espacial do SPI durante La nina Canônico

Em anos de EN Modoki o Leste alagoano apresenta-se mais seco que o Sertão e Agreste, respectivamente (Figura 12). Para eventos de LN é esperado, para o NEB, precipitação acima da média; no entanto, os eventos de LN do tipo Modoki, no Leste e Sertão alagoanos foram de chuvas abaixo da média, com SPI negativo, e um pouco acima da média no Agreste (Figura 13).

Os maiores valores registrados em fases de ENOS equivalem aos maiores valores também ocorridos durante Dipolo do Atlântico (Figura 14).

Assim como em Macedo et al (2010), que apontaram o semiárido paraibano como o que apresentou menores valores de SPI; em Alagoas, o Sertão alagoano, inserido na região semiárida, também apresentou nas 5 modalidades de ENOS, os menores valores de SPI, e tendência de ocorrência de secas. Para eventos de LN é esperado, para o NEB, precipitação acima da média; no entanto, os eventos de LN do tipo Modoki, no Leste e Sertão alagoanos foram de chuvas abaixo da média, com SPI negativo, e um pouco acima da média no Agreste. Já para eventos de LN Canônico, todas as 3 macroregiões apresentaram SPI positivo, com precipitação acima da média, apresentando maiores valores no Leste/litoral alagoano, e diminuindo os totais pluviométricos à medida que adentra-se no

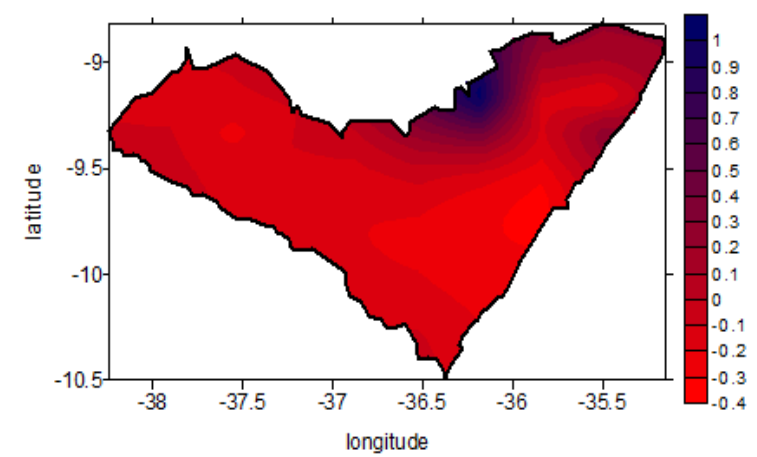

Figura 9. Distribuição espacial do SPI durante La Niña Fraca

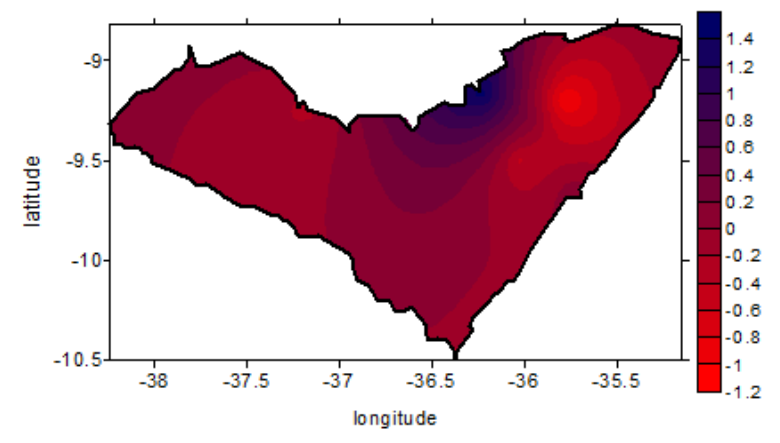

Figura 11. Distribuição espacial do SPI durante La nina Modoki

continente, com valor um pouco menor no Agreste alagoano e registrando menores precipitações no Sertão. Desta forma, durante o LN Canônico seguiu-se o padrão esperado.

Quando o LN é Forte, o mais beneficiado é o Agreste alagoano, seguido pela região do Sertão e, posteriormente pelo Leste alagoano. Para LN Moderada, as regiões do Sertão e Agreste são os mais prejudicados com chuvas abaixo da média, ficando também o Leste com chuva abaixo da média mas com SPI de aproximadamente $-0,1$, o que o coloca em categoria quase normal. Em eventos de LN Fraca, somente o leste alagoano apresentou SPI positivo.

Bonfim e Da Silva (2019) verificaram para a Bacia hidrográfica Aguapeí-Peixe (SP) que chuvas acima da média ocorreram com maior frequência na fase Canônica do ENOS, como também encontrado aqui, para Alagoas, durante LN Canônica.

As variações dos valores de SPI (Figura 15) apresentaram-se próximos, com exceção de alguns anos com eventos extremos como no Sertão alagoano, região com maiores SPIs negativos, em 1970, 1974, 1975, 1980, 1981, 1984; no Agreste alagoano, em 1981, 1990, 1995, 1997, 1998; e para o Leste alagoano, região com maiores SPIs positivos, 1964, 2001, 2002, 2003, 2004, 2009, 
2010, 2012, 2013. As causas climáticas dos principais extremos estão explicadas através das análises de ondeletas das Figuras 16 a 18.

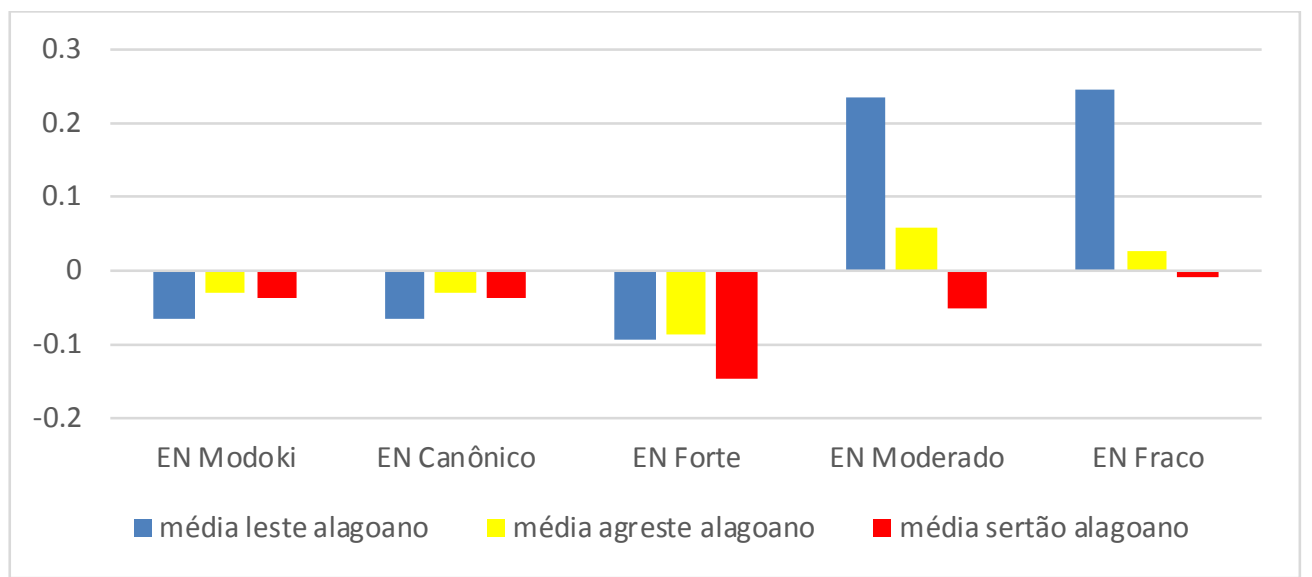

Figura 12. SPI nas macroregiões de Alagoas durante as fases de El Niño

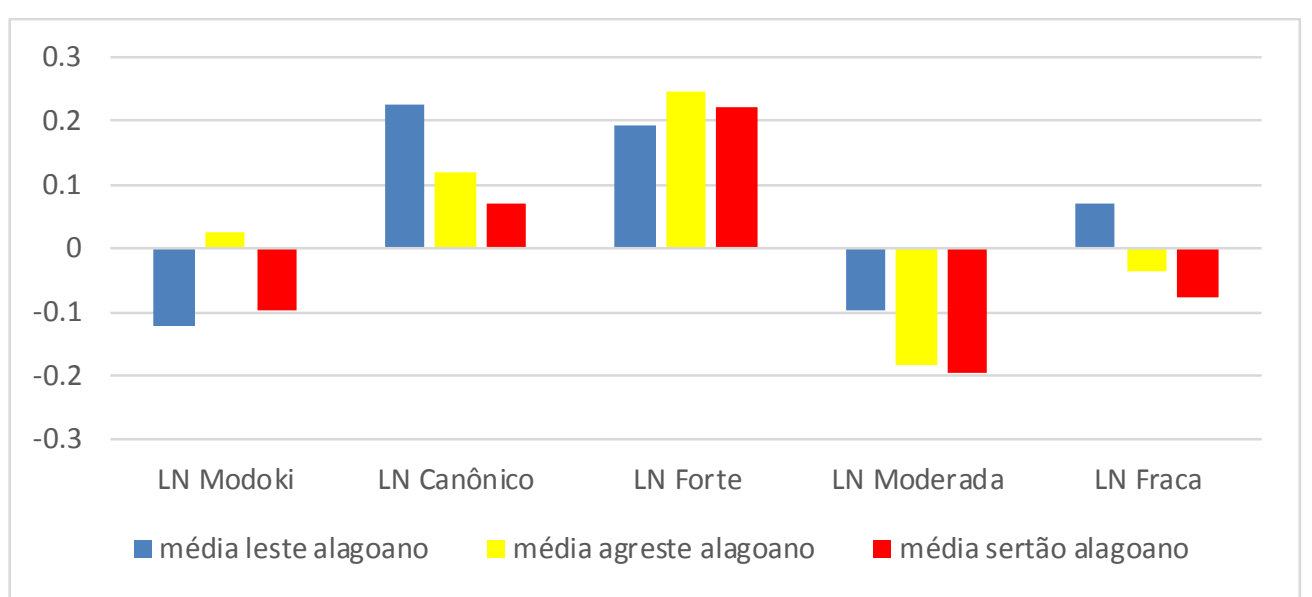

Figura 13. SPI nas macroregiões de Alagoas durante as fases de La Niña .

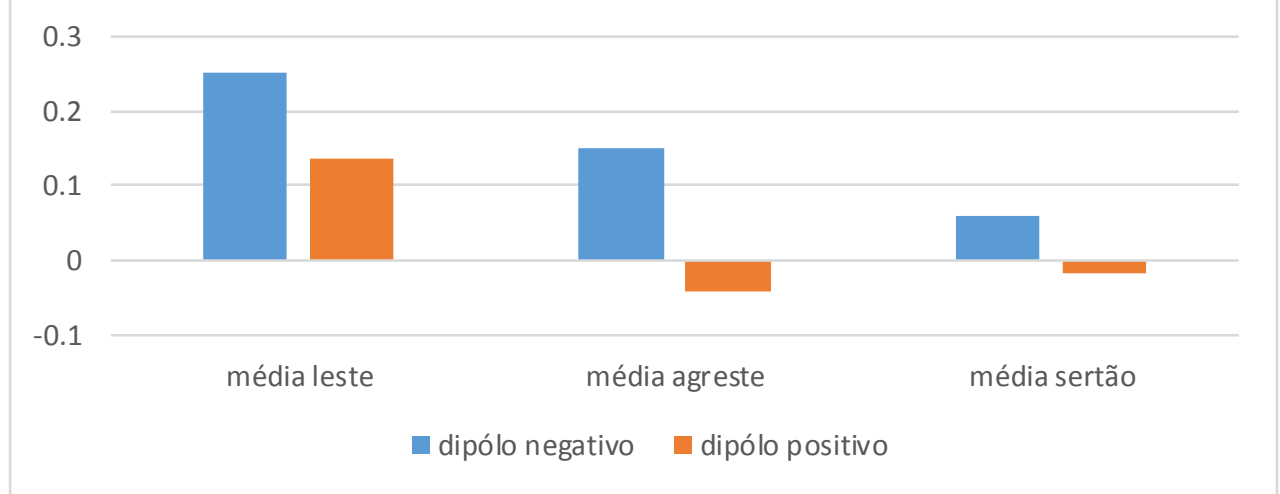

Figura 14. SPI nas macroregiões de Alagoas durante as fases do Dipólo do Atlântico.

Os maiores valores registrados em fases de ENOS equivalem aos maiores valores também ocorridos durante Dipolo do Atlântico. O Leste alagoano tem chuvas acima da média tanto em Dipólo positivo quanto negativo (Figura 13); no entanto, o SPI é o dobro em valorquando há Dipólo negativo, com Atlântico Sul aquecido. O Agreste e Sertão apresentaram SPI positivo durante Dipólo negativo, em decorrência de maior TSM do AT e consequentemente formação de nuvens e chuva trazidas ao continente. No entanto, durante Dipólo positivo, o SPI apresenta-se negativo com chuvas abaixo da média.

Geograficamente, o Dipólo negativo influencia positivamente na precipitação do leste de Alagoas, diminuindo a chuva que proporciona à 
medida que adentra o continente, causando menos chuva no Sertão, e ainda menos no Agreste, com SPI negativos mais intensos. Moura e Shukla (1981) sugeriram que as condições dinâmicas e termodinâmicas associadas ao Dipólo meridional de ATSM interferem sensivelmente na posição e intensidade da ZCIT que, por sua vez, influencia a precipitação no NEB.

Em todas análises de ondeletas (Figuras 16 a 18) a escala dominante foi a de 11 anos, a qual tem relação com Manchas solares (KERR, 1996; ECHER et al., 2003, MOLION, 2005) e pode ser decorrente da variabilidade do Dipolo do Atlântico (SERVAIN, 1999; CLAUZET e WAINER, 1999). Esse resultado está de acordo com Andreoli et al. (2004), que comprovaram que a influência do Oceano Atlântico é maior e contribui mais fortemente em áreas do Nordeste brasileiro que o Oceano Pacífico.

Condições de El Niño e GRAD no AT ocorrendo simultaneamente, atuam para aumentar (GRADP) ou diminuir (GRADN) as magnitudes das anomalias de precipitação conforme resultados de Pezzi e Cavalcanti (2001), Souza et al. (2004) e Ambrizi et al. (2004) os quais ainda afirmam que em certas situações o efeito da variabilidade do Atlântico pode sobrepor-se ao efeito da variabilidade no Oceano Pacífico, associada ao ENOS, e em outros não.

Os altos valores de precipitação no leste alagoano são em decorrência da junção de fenômenos e sistemas meteorológicos de escalas temporais distintas como escala sazonal $(0,25$ anos), escala semestral ( 0,6 anos), interanual curta (1 ano), entre $1-2$ anos ligada ao ENOS, forte sinal de até 8 anos, ligado ao ENOS estendido (Clauzet e Wainer, 1999), Dipólo do Atlântico (entre 7 a 11 anos) e de 11 anos ligada ao ciclo de Manchas solares; tendo como principal extremo o período entre 2000 a 2005 comaltos valores de precipitação (Figura 1). Neste período houve atuação de La Niña moderado e sinal persistente de ENOS estendido, conforme CPTEC (2017). Por fim, a escala secundária nesta macrorregião é a entre $1 \mathrm{e}$ 2 anos do ENOS e a de 2 a 8 anos do ENOS estendido.

Para as macrorregiões do Agreste e Sertão alagoanos, a união de escalas distintas promoveram eventos extremos que merecem atenção, em 1975/76 e 1981. A junção das escalas semestral, interanual, escala entre 1-2 anos de ENOS, escala de ENOS estendido e escala de 11 anos (Dipólo e Manchas solares) potencializou os totais pluviométricos locais, como também sugeriram Hastenrath e Heller (1977), Rockwood e Maddox (1988), Markhann (1974), Hastenrath e Kaczmarczyk (1981) e Da Silva (2017). As escalas secundárias nessas macrorregiões foram as do ENOS estendido e semestral.

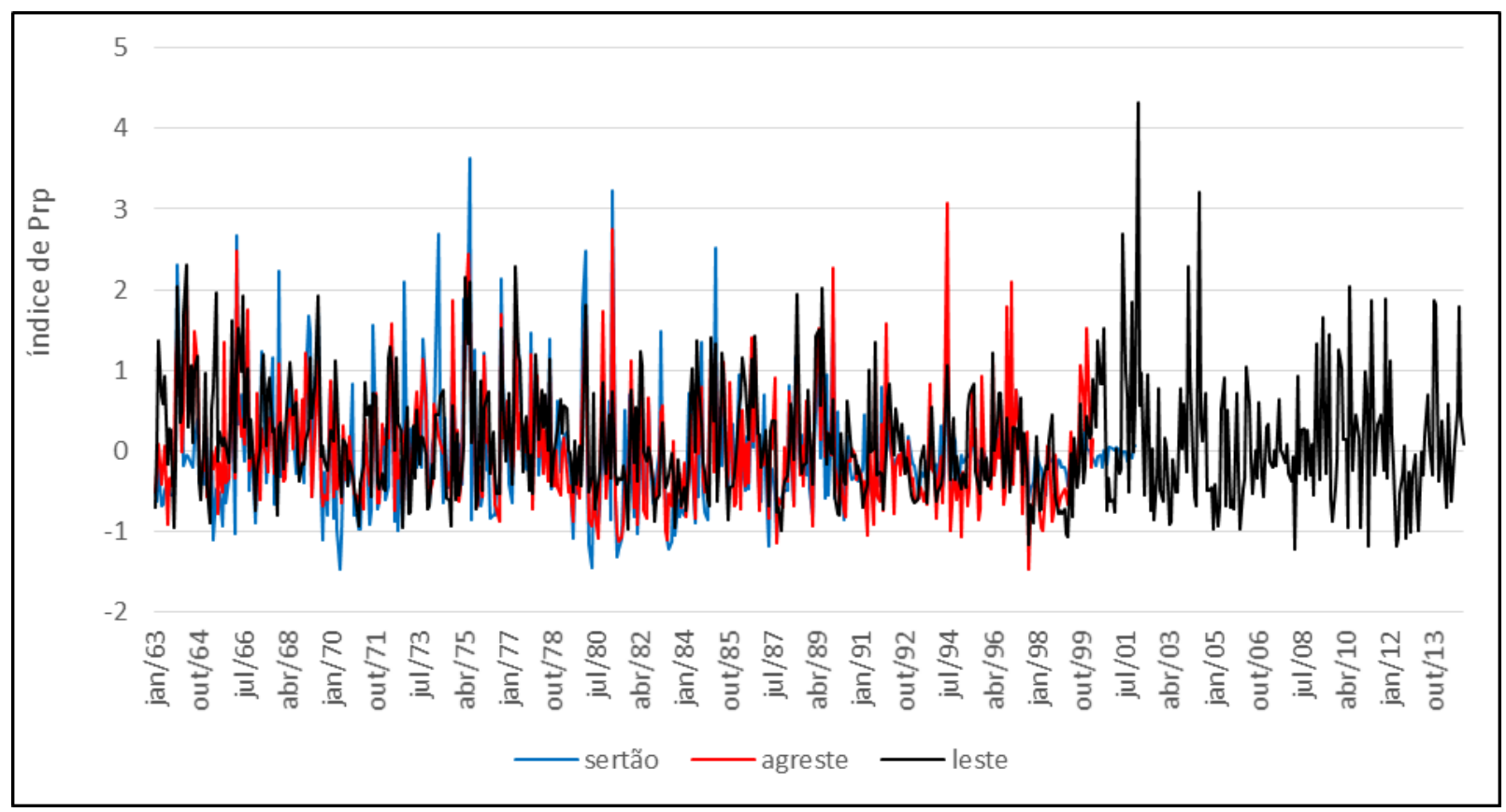

Figura 15. Séries de SPI para as 3 macroregiões a lagoanas. 

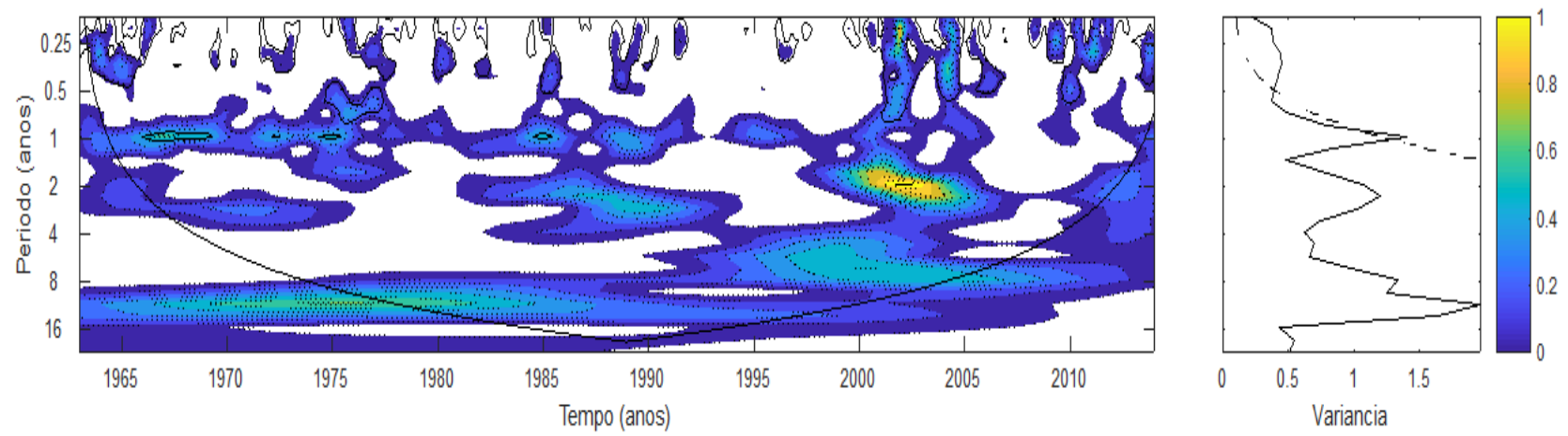

Figura 16.a) Espectro de potência de ondaleta (EPO) para Prp. no Leste Ala goano. Contornos sombreados correspondem a variâncias norma lizadas significa tivas a o nível de 5\%; b) Espectro de potência global (EPG), com o contorno tracejado indicando que o EPG é significativo ao nível de confiança de $95 \%$.
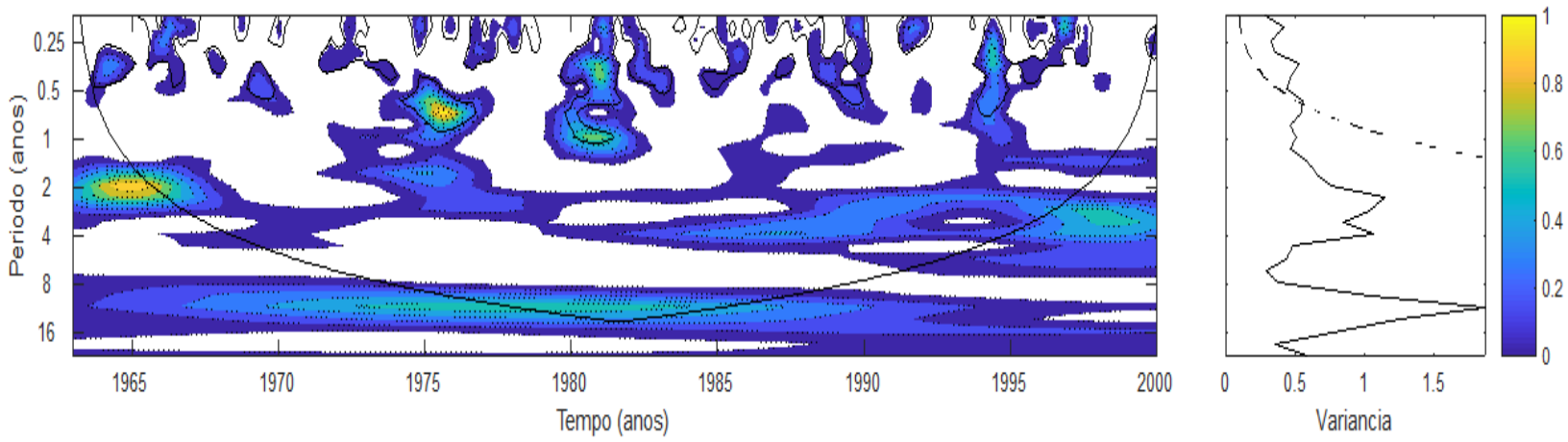

Figura 17. a) Espectro de potência de ondaleta (EPO) para Prp. no Agreste Alagoano. Contornos sombreados correspondem a variâncias normalizadas significativas ao nível de 5\%; b) Espectro de potência global (EPG), com o contorno tracejado indicando que o EPG é significativo ao nível de confiança de $95 \%$.
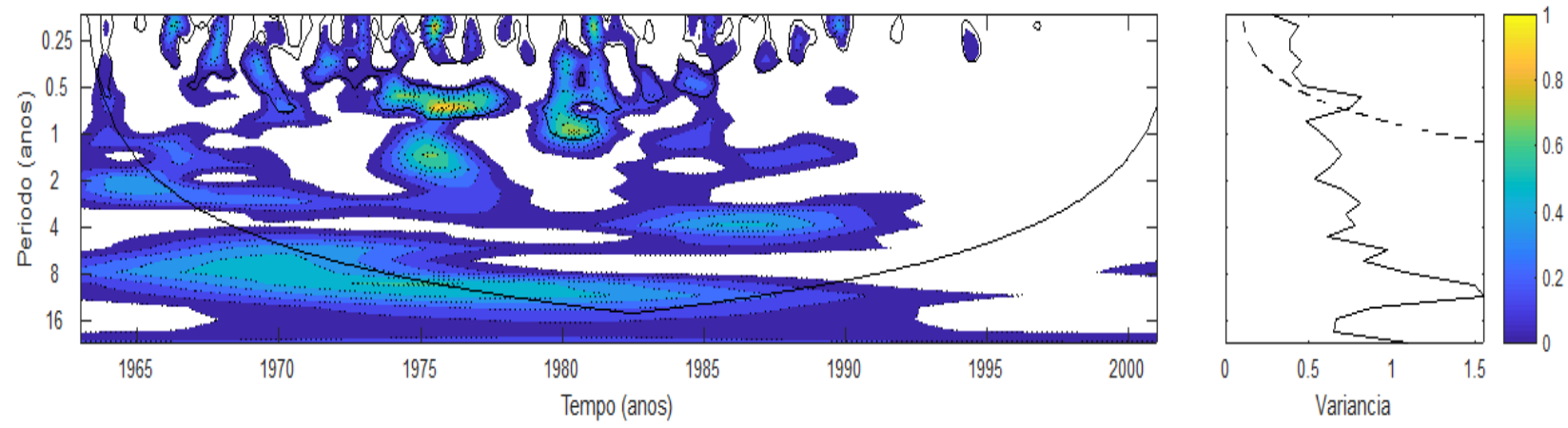

Figura 18. a) Espectro de potência de ondaleta (EPO) para Prp. no Sertão Ala goano. Contornos sombrea dos correspondem a variância s norma liza das significa tivas a o nível de 5\%; b) Espectro de potência global (EPG), com o contorno tracejado indicando que o EPG é significativo ao nível de conf iança de $95 \%$.

Silva., D., F., Neto., P., F., S., Silva., S., D., Lima., M., J., S., Cavalcante., I., B., S Oliveira., S., T., Mendonça., H., S., Batista., B., A., Rocha., L., H., S Almeida., H., R., R., C., Pereira., M., P., S., Araújo., L., E. 

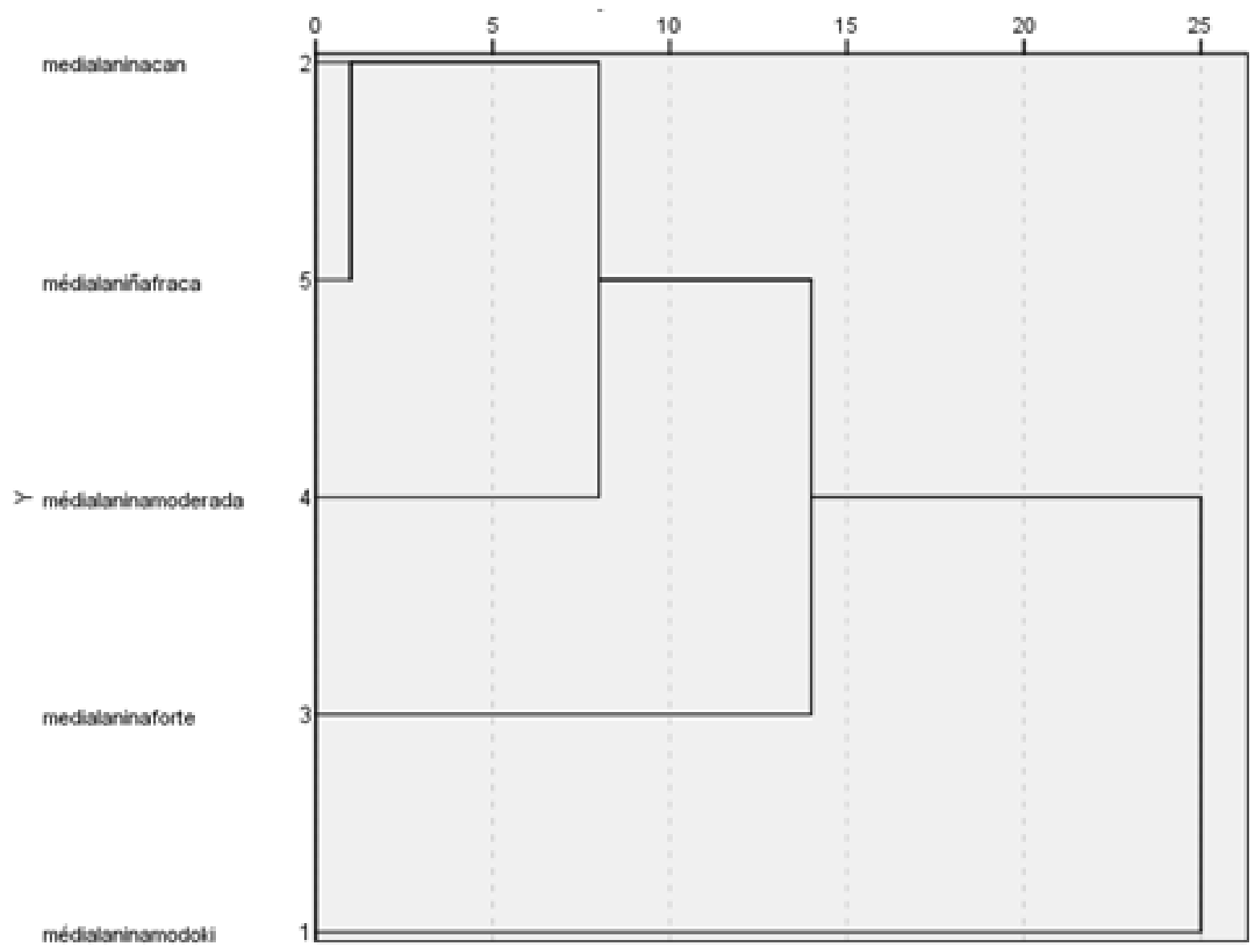

Figura 19. Dendograma da análise de agrupamentos para séries de SPI durante eventos de La Niña fraca,forte, moderada, Canônica e Modoki. Eixo X representa a distância euclidiana quadrática.

O dendograma (Figura 19) mostra semelhança direta entre os SPIs da La Niña Fraca e La Niña Canônica (reforçadas pelas correlações matemáticas e com significância estatísticas na Tabela 6), e essas, por sua vez, semelhança não tão direta com La Niña moderada e menor semelhança com La Niña Forte; ou seja, SPI durante La Niña Canônica tem mais semelhança com La Niña Fraca e alguns pontos análogos com as outras duas categorias. Já La Niña Modoki tem semelhança indireta com os outros tipos de La Niña.

Nos casos de El Niño (Figura 20), as categorias fraco e moderado tem semelhança direta, reforçadas pelas correlações matemáticas e com significância estatísticas (Tabela 7); são os que mais se assemelham. O tipo El Niño forte tem semelhança não tão direta com El Niño Canônico, conforme também verificado nas Figuras 2 e 5. Ambos têm pouca semelhança com El Niño Modoki, corroborando com Grim e Tedeschi (2009). Por fim, o primeiro grupo (El Niño fraco e Moderado) tem semelhança indireta com o segundo grupo (El Niño Canônico, Forte e
Modoki), significando que não há semelhança, ou quase nenhuma semelhança.

Os resultados encontrados aqui também estão de acordo com os de Bonfim e Da Silva (2019) que relacionaram a pluviometria da Bacia hidrográfica Aguapeí-Peixe (SP) às classes dos eventos classificados pelo SPI. Os autores associaram El Niño Canônico há uma maior possibilidade de ocorrência de chuvas extremas, que para o Sudeste do Brasil, ocorrem durante El Niño forte. Para Alagoas o El Niño Canônico está ligado ao El Niño Forte.

Os autores também associaram La Niña Canônica a casos de secas leves. La Niña no Sudeste causa seca. Já em Alagoas, La Niña Canônica apresentou aqui relação com La Niña Fraca, mesmo La Niña propiciar chuvas acima da média, na maioria dos casos.

Matematicamente, as categorias de El Niño e La Niña forte e fraca apresentaram melhores correlações com ENOS Modoki e Canônico (Tabelas 6 e 7), e já ENOS moderada com categoria fraca; sugerindo padrão para Alagoas. 


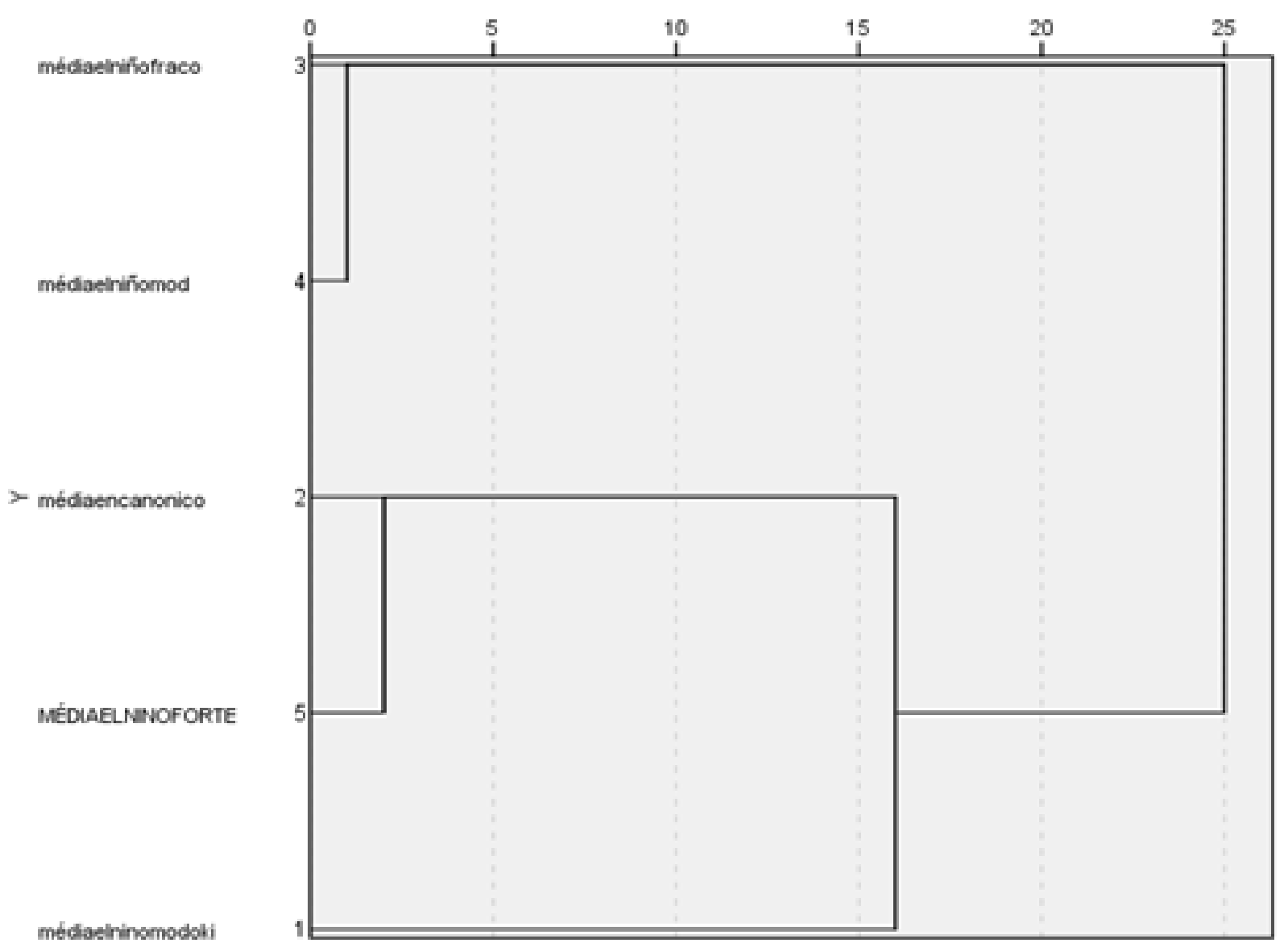

Figura 20. Dendograma da análise de agrupa mentos para séries de SPI durante eventos de El Niño fraco, forte, modera do, Canônico e Modoki. Eixo X representa a distância euclidiana quadrática.

Tabela 6. Correlações matemáticas entre categorias de La Niña.

\begin{tabular}{|c|c|c|c|c|c|}
\hline & $\begin{array}{c}\text { Média La Niña } \\
\text { Modoki }\end{array}$ & $\begin{array}{c}\text { Média La Niña } \\
\text { Canônica }\end{array}$ & $\begin{array}{c}\text { Média La Niña } \\
\text { Forte }\end{array}$ & $\begin{array}{c}\text { Média La Niña } \\
\text { Moderada }\end{array}$ & $\begin{array}{c}\text { Média La Niña } \\
\text { Fraca }\end{array}$ \\
\hline Média La Niña Modoki & - & 0,875 & 0,842 & 0,793 & 0,838 \\
\hline Média La Niña Canônica & 0,875 & - & $0,919 *$ & 0,819 & $0,986 *$ \\
\hline Média La Niña Forte & 0,842 & $0,919 *$ & - & 0,829 & 0,895 \\
\hline Média La Niña Moderada & 0,793 & 0,819 & 0,829 & - & 0,855 \\
\hline Média La Niña Fraca & 0,838 & $0,986^{*}$ & 0,895 & 0,855 & - \\
\hline
\end{tabular}

*significante ao nível de $95 \%$

Tabela 7. Correlações matemáticas entre categorias de El Niño

\begin{tabular}{lr|r|r|r|r}
\hline & $\begin{array}{c}\text { Média El Niño } \\
\text { Fraco }\end{array}$ & $\begin{array}{c}\text { Média El Niño } \\
\text { Moderado }\end{array}$ & $\begin{array}{c}\text { Média El Niño } \\
\text { Forte }\end{array}$ & $\begin{array}{c}\text { Média El Niño } \\
\text { Modoki }\end{array}$ & $\begin{array}{c}\text { Média El Niño } \\
\text { Canônico }\end{array}$ \\
\hline Média El Niño Fraco & - & $0,867^{*}$ & $0,879^{*}$ & 0,746 & 0,820 \\
\hline Média El Niño Moderado & $0,867^{*}$ & - & 0,787 & 0,623 & 0,588 \\
\hline Média El Niño Forte & $0,879^{*}$ & 0,787 & - & 0,758 & - \\
\hline Média El Niño Modoki & 0,746 & 0,623 & 0,758 & & 0,853 \\
\hline Média El Niño Canônico & 0,820 & 0,588 & 0,853 & 0,647 & - \\
\hline
\end{tabular}

*significante ao nível de $95 \%$ 


\section{Conclusões}

Eventos de EN Canônico e Modoki apresentaram o mesmo ef eito nas 3 macrorregiões de Alagoas. EN Modoki e Fracos promoveram aumento de chuvas na região Leste. Já EN Fortes causaram diminuição de precipitação no Sertão. Eventos de LN Canônica causaram aumento significativo nas chuvas das 3 macrorregiões, mas o ef eito foi melhor em LN Forte. Durante as fases do Dipólo do Atlântico, a fase negativa gerou SPI positivo em todo estado, e na fase positiva, houve diminuição do SPI na região Leste, e registro de SPI negativo no Sertão e Agreste.

Através do SPI, foram apontados os principais eventos extremos para as macrorregiões alagoanas. Em todas análises de ondeletas, a escala dominante foi a de 11 anos, a qual tem relação com Manchas solares e pode ser decorrente da variabilidade do Dipolo do Atlântico, corroborando com Andreoli et al. (2004), que comprovaram que a influência do Oceano Atlântico é maior e contribui mais fortemente em áreas do Nordeste brasileiro que o Oceano Pacífico. A junção das escalas semestral, interanual, escala entre 1-2 anos de ENOS, escala de ENOS estendido escala de 11 anos (Dipólo e Manchas solares) potencializou os totais pluviométricos locais, e a falta dos mesmos provocou eventos de secas.

Verificou-se semelhança entre os SPIs da La Niña Fraca e La Niña Canônica, e entre o El Niño Canônico está ligado ao El Niño Forte. Já matematicamente, as categorias de El Niño e La Niña forte e fraca apresentaram melhores correlações com ENOS Modoki e Canônico, sugerindo padrão para Alagoas

\section{Referências}

Ambrizzi, T.; Souza, E. B.; Pulwarty, R. S. 2004.. The Hadley and walker regional circulations and associated ENSO impacts on South American seasonal rainfall. In: The Hadley Circulation: Present, Past and Future. Diaz H.F. and Bradley R.S. (Eds.). Kluwer Publishers, Chapter 7, 203-235,

Andreloi, R.V.; Kayano, M.T.; Guedes, R. L.; Oyama, M. D.; Alves, M. A. S. 2004.. A influência da temperatura da superfície do mar dos oceanos Pacífico e Atlântico na variabilidade de precipitaçãoem Fortaleza.
Revista brasileira de meteorologia, 19, .337-344,

Andreoli, R. V.; Kayano, M. T. 2007. A importância relativa do atlântico tropical sul e pacífico leste na variabilidade de precipitação do Nordeste do Brasil. Revista brasileira de Meteorologia, São Paulo, 22, 63-74.

Ashok, K; Behera, S. K.; Rao, S. A.; Weng, H. e Yamagata, T. El 2007. Niño Modoki and its possible teleconnection. Journal of Geophysical Research, 112, C11007, doi:10.1029/2006JC003798

Bonfim, O. E. T.; Da Silva, D. F. 2018. Aplicação do índice de precipitação normalizada nos casos de ENOS canônico e Modoki ocorridos na Bacia hidrográfica AguapeíPeixe/SP. Revista Ibero Americana de Ciências Ambientais, 9, 83-94,.

Brunini, O.;Zullo Junior, J.; Pinto, H.S.; Assad, E.; Sawazaki, E.; Duarte, A.P.; Patterniani, M.E.Z. Riscos climáticos para a cultura de milho no Estado de São Paulo. Revista Brasileira de Agrometeorologia, Passo Fundo, v.9, n.3, p.519-526, 2001.

Clauzet, G.; Wainer, 1999 I. Identificação da variabilidade de baixa frequência em algumas regiões da Costa Sudeste Nordeste do Brasil. Revista Brasileira Oceanografia, 47, p. $69-78$.

CPTEC - Centro de Previsão de Tempo e Estudos Climáticos, 2017. Disponível em www.cptec.inep.br. Acesso em: 02 de junho de 2019.

Da Silva, D. F. 2017. Aplicação de análises de Ondeletas para detecção de ciclos e extremos pluviométricos no Leste do Nordeste do Brasil. Revista Brasileira de Meteorologia, 32, 187 - 198,.

Echer, E.; Rigozo, N.R.; Nordemann, D. J. R.; Vieira, L. E. A.; Prestes, A.; Faria, H. H. O número de manchas solares, índice da atividade do sol. Revista Brasileira de Ensino de Física, São Paulo, 25, 2003.

Farias, W. R. G.; Da Silva, D. F.; Araújo, L. E.; Nascimento, M. G. 2005. Variação climática da precipitação no Estado de Pernambuco através de análise de componentes principais, IN SIMPÓSIO INTERNACIONAL DE CLIMATOLOGIA, 2005, Anais..., v.1, Fortaleza.

Guedes, R. V. S.; Lima, F. J. L.; Amanajás, J. C.; Braga, C. C. 2010.. Análise em componentes principais da precipitação 
pluvial no estado do Piauí e agrupamento pelo método de Ward. Revista de Geografia, Recife, 218-233,

Guedes, R. V. S; Macedo, M. J. H.; Sousa, F. A. S. Análise espacial de eventos de secas com base no índice padronizado de precipitação e análise de agrupamento, Revista Brasileira de Ciências Ambientais, 55-65, 2012.

Grimm, A. M. 2004. The El Niño Impact on Summer Monsoon in Brazil: Regional Processes versus Remote Influences. Journal of Climate, 16, 263-280, 2003. GRIMM, A. M. How do La Niña events disturb the summer monsoon system in Brazil? Climate Dynamics, 22, 123-138,

Grimm, A. M.; Barros, V. R. e Doyle, M. E. 2000.. Climate variability in Southern South America associated with El Niño and La Niña events. Journal of Climate, 13, 35-58,

Grimm, A. M.; Tedeschi, R. G. 2009. ENSO and extreme rainfall events in South America. Journal of Climate, 22, 1589-1609,.

Guimarães, R. M. L.; Ball, B. C.; Tormena, C. A.; Girabola, N. E. F. B.; Silva, A. P. 2013. Relating visual evaluation of soil structure to other physical properties in soils of contrasting texture and management. Soil \& Tillage Research, 127, .92-99,.

Hastenrath, S.; Heller, L. Dynamics of climatic hazards in Northeast Brazil. Quartely Journal Royal Meteorological Society, 103, 77-92, 1977.

Hastenrath, S.; Kaczmarczyk, E. B. 2009.. On spectra and coherence of tropical climate anomalies. Tellus, 33, 453 - 462, 1981.

Kao, H.; Yu, J. Contrasting Eastern-Pacific and Central-Pacific Types of ENSO. Journal of Climate, 22, 615-632,

Kerr, R. A. 1996. A now dawn for sun-climate links? Science, Washington, DC, 271, 1360-1361,

Lima, F. J. L.; Amanajás, J. C.; Guedes, R. V. S.; Silva, E. M. 2010. Análises de Componente Principal e de Agrupamento para estudo de ventos para a geração de energia eólica na região do Ceará, Paraíba, Pernambuco e Rio Grande do Norte, Brasil. Revista Ambi-Água, Taubaté, 5, 188-201,. (doi:10.4136/ambi-agua.147)

Macedo, M. J. H; Guedes, R. V. S; Sousa, F. A. S; Dantas, F. R. C. 2010.Análise do Índice Padronizado de Precipitação para o estado da Paraíba, Brasil. Revista Ambi-Água, Taubaté, 5, 204-214,
Markhann, C. G. Apparent periodicities in rainfall at Fortaleza. Journal of Applied Meteorology and Climatology, Ceará, 13, $176-179,1974$.

Mckee, T. B.; Doesken, N. J.; Kleist, J. 1993. The relationship of drought frequency and duration of time scales. In: CONFERENCE ON APPLIED CLIMATOLOGY. 1993, Anais.... Anaheim: American Meteorological Society, p.179-186.

Moore, D. S. The Basic Practice of Statistics. New York, 200 p., 2007.

Molion, L. C. B. 2005. Aquecimento global, El Niños, manchas solares, vulcões e Oscilação Decadal do Pacífico. Revista Climanálise, Cachoeira Paulista, 3, 1-5,

Moura, A. D.; Shukla J. On the dynamics of droughts in Northeast Brazil: observations, theory, and numerical experiments with a general circulation model. Journal Atmospheric Science, 38, 2653-2675, 1981.

Pezzi, L. P.; Cavalcanti, I. F. A. 2001. The relative importance of ENSO and tropical Atlantic sea surface temperature anomalies for seasonal precipitation over South America: a numerical study. Climate Dynamic, $17, .205-212$,

Polzin, D.; Hastenrath, S. 2014.. Climate of Brazil's Nordeste and Tropical Atlantic Sector: Preferred Time scales of variability. Revista Brasileira de Meteorologia, 29, 153-160,

Rockwood, A. A.; Maddox, R. A. Mesoscale and synoptic scale interactions leading to intense convection: The case of 7 June 1982. Weather and Forecasting, 3, 51-68, 1988.

Santos, S. R. Q.; Braga, C. C.; Sansigolo, C. A.; Santos A. P. P. Determinação de Regiões Homogêneas do Índice de Precipitação Normalizada (SPI) na Amazônia Oriental. Revista Brasileira de Meteorologia, 32, 111-122, 2017

Santos, F. A. S.; Anjos, R. J. 2001. Utilização do Índice de precipitação Padronizada (SPI) no monitoramento da seca no Estado de Pernambuco. I: XII CONGRESSO BRASILEIRO DE AGROMETEOROLOGIA, 2001, Anais..., Sociedade Brasileira de Agrometeorologia, Fortaleza, p.121-122. 
Servain, J.; Wainer, I.; Mccreary, J. P.; Dessier, A. Relationship between the equatorial and meridional modes of climatic variability in the Tropical Atlantic. Geophysical Research Letters, 26(4), 485-488, 1999. doi: 10.1029/1999GL900014

Souza, E. B.; Ambrizzi, T.; Coelho, C. A. S. 2004. Two episodes with reversed impacts on the regional precipitation of the northeastem South America. Meteorológica, 29, 5-16, Torrence, C.; Compo, G. P.: A practical guide to wavelet analysis. Bulletin of the American Meteorological Society, 79, 61-78, 1998.
Unal, Y.; Kindap, T.; Karaca, M. 2003. Redefining the climate zones of Turkey using cluster analysis. International Journal of Climatology, 23, 1045-1055,.

Weng, H.; Ashok, K.; Behera, S. K.; Rao, S. A. e Yamagata, T. 2007. Impacts of recent El Niño Modoki on dry/wet conditions in the Pacific rim during boreal summer. Climate Dynamics, 29, 113-129, , DOI 10.1007/s00382-007-0234-0 